\title{
Extreme white colouration of frogfish Antennarius maculatus due to coral bleaching event
}
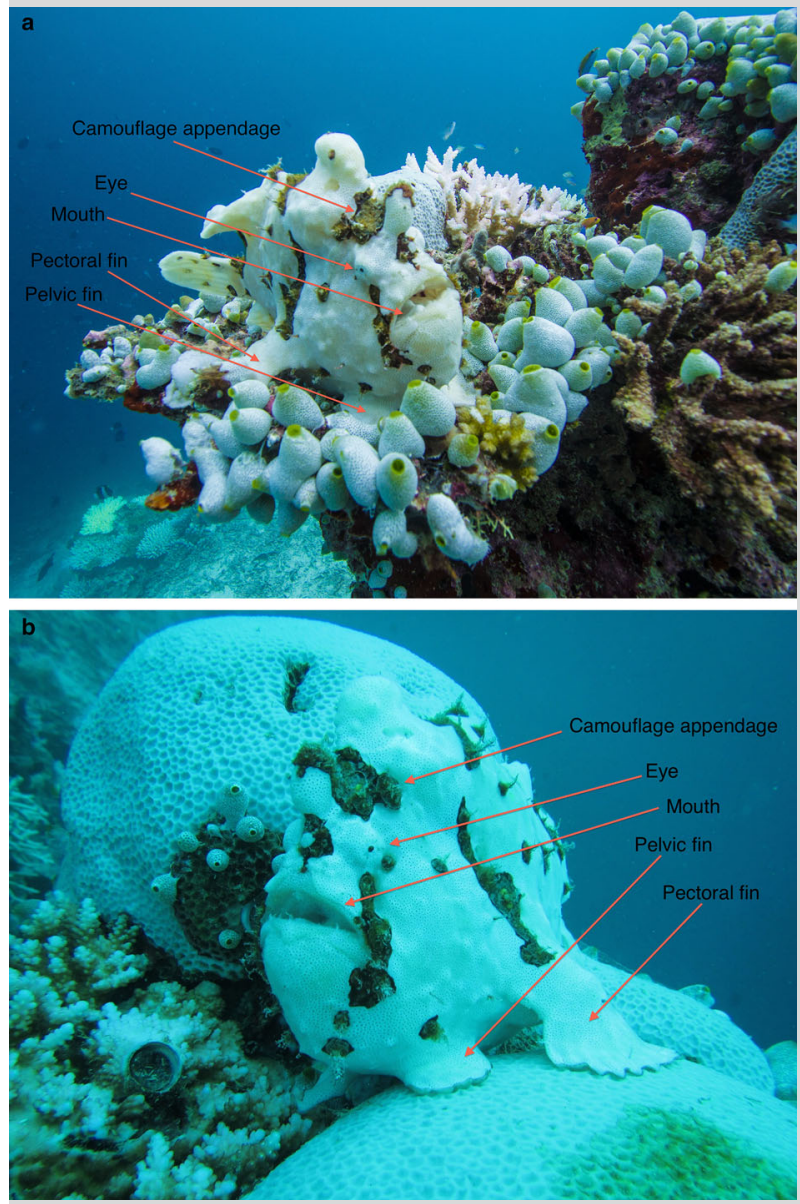

Fig. 1 Warty frogfish Antennarius maculatus camouflaged against bleached Acropora (a) and Goniastrea (b) coral colonies
An individual of the warty frogfish species Antennarius maculatus was observed camouflaging itself against fully bleached corals at $10 \mathrm{~m}$ depth at the Velidhoo Island resort reef $\left(4^{\circ} 11^{\prime} 41.35^{\prime \prime} \mathrm{N}\right.$, $\left.72^{\circ} 49^{\prime} 20.55^{\prime \prime} \mathrm{E}\right)$ in North Ari Atoll, Maldives, on 19 May 2016. The frogfish was approximately $20 \mathrm{~cm}$ long, and being completely white, matching the bleached coral background, it displayed several camouflage flaps and appendages on its body that resembled the turf algae growing on dead parts of a Goniastrea coral skeleton. The individual was first spotted resting at the bottom of the reef slope, amongst Didemnum molle sea squirts, bleached corymbose Acropora and bleached Goniastrea colonies (Fig. 1a). Within a 5-min period, the individual had moved to the other side of the coral block where it was surrounded entirely by a bleached and dead skeleton of a Goniastrea colony, as well as patches of turf algae (Fig. 1a,b). Because Antennarius maculatus is a sedentary species that rarely moves location, it is probable that this individual changed its colouration to match the bleached coral. Coral bleaching mostly likely occurred in late April or early May 2016 given that the sea surface temperature anomalies were above the $31{ }^{\circ} \mathrm{C}$ coral bleaching threshold in the Maldives at that time (NOAA Coral Reef Watch 2016). Individuals from the $A n$ tennarius genus have been known to change colour in both experimental aquaria and in field observations (Pietsch 1984). However, it would be interesting to observe whether the frogfish would change colour to match the coral as the coral either regained its pigmentation after bleaching or died and was covered in turf algae or other benthic organisms. This sighting is an interesting example of the extreme changes in colouration that frogfish are capable of, and of how frogfish may react to increasingly frequent coral bleaching events around the world.

\section{References}

NOAA Coral Reef Watch (2016) NOAA coral reef watch 50-km satellite virtual station time series data for Maldives. Silver Spring, Maryland, USA: NOAA coral reef watch. Data set accessed at http://coralreefwatch.noaa.gov/satellite/vs/index.php

Pietsch TW (1984) The genera of frogfishes (family Antennariidae). Copeia 1984:27-44

G. Grimsditch $(\bowtie) \cdot$ A. Basheer

International Union for the Conservation of Nature Maldives, Malé, Maldives

e-mail: gabriel.grimsditch@iucn.org

D. E. P. Bryant

School of Biological Sciences, University of Queensland, St Lucia, QLD 4072, Australia

D. E. P. Bryant

Global Change Institute, University of Queensland, St Lucia, QLD 4072, Australia

D. E. P. Bryant

ARC Centre for Excellence for Reef Studies, University of Queensland, St Lucia, QLD 4072, Australia

Received: 26 July 2016/ Accepted: 31 August 2016/Published online: 20 September 2016

Coral Reefs (2017) 36:167

(C) Springer-Verlag Berlin Heidelberg 2016

DOI 10.1007/s00338-016-1500-6 